Revue d'histoire de l'Amérique française

7S REVUE D.HISTOIRE DE L'AMÉRIQUE FRANÇAISE

\title{
La presse dans le discours des évêques québécois de 1764 à 1914
}

\section{Jean de Bonville}

Volume 49, numéro 2, automne 1995

URI : https://id.erudit.org/iderudit/305416ar

DOI : https://doi.org/10.7202/305416ar

Aller au sommaire du numéro

\section{Éditeur(s)}

Institut d'histoire de l'Amérique française

\section{ISSN}

0035-2357 (imprimé)

1492-1383 (numérique)

Découvrir la revue

Citer cet article

de Bonville, J. (1995). La presse dans le discours des évêques québécois de 1764 à 1914. Revue d'histoire de l'Amérique française, 49(2), 195-221.

https://doi.org/10.7202/305416ar

\section{Résumé de l'article}

Dans leurs communications officielles avec les clercs et les fidèles de leur diocèse, les évêques québécois abordent un grand nombre de sujets parmi lesquels le thème de la culture, et particulièrement celui de la presse, n'occupent que la portion congrue. Les documents consacrés partiellement ou entièrement à ces sujets sont publiés à partir du milieu du XIX ${ }^{\mathrm{e}}$ siècle. Dans ces mandements, lettres pastorales et circulaires, les évêques visent un double objectif. Tout d'abord, lutter contre l'influence de ce qu'ils considèrent comme de mauvais journaux ou une mauvaise presse en général; ensuite, encourager la diffusion de bonnes publications et le développement de la presse catholique. Le discours episcopal apparaît adapté à la situation, c'est-à-dire que ses auteurs tiennent compte du rapport de force qui les oppose à leurs adversaires et du support dont ils disposent auprès de leurs fidèles.
Tous droits réservés @ Institut d'histoire de l'Amérique française, 1995
Ce document est protégé par la loi sur le droit d'auteur. L’utilisation des services d'Érudit (y compris la reproduction) est assujettie à sa politique d'utilisation que vous pouvez consulter en ligne.

https://apropos.erudit.org/fr/usagers/politique-dutilisation/ 


\title{
LA PRESSE DANS LE DISCOURS DES ÉVÊQUES QUÉBÉCOIS DE 1764 À $1914^{1}$
}

\author{
JEAN DE BONVILLE \\ Département d'information et de communication \\ Université Laval
}

\section{RÉSUMÉ}

Dans leurs communications officielles avec les clercs et les fidèles de leur diocèse, les évêques québécois abordent un grand nombre de sujets parmi lesquels le thème de la culture, et particulièrement celui de la presse, n'occupent que la portion congrue. Les documents consacrés partiellement ou entièrement à ces sujets sont publiés à partir du milieu du XIX ${ }^{\mathrm{e}}$ siècle. Dans ces mandements, lettres pastorales et circulaires, les évêques visent un double objectif. Tout d'abord, lutter contre l'influence de ce qu'ils considèrent comme de mauvais journaux ou une mauvaise presse en général; ensuite, encourager la diffusion de bonnes publications et le développement de la presse catholique. Le discours épiscopal apparaît adapté à la situation, c'est-à-dire que ses auteurs tiennent compte du rapport de force qui les oppose à leurs adversaires et du support dont ils disposent auprès de leurs fidèles.

\section{ABSTRACT}

In their official communications with the clergy and the faithful of their diocese, Québec bishops addressed many subjects, the press or even cultural matters rarely among them. Documents dealing entirely or partly with the press were published from the middle of the nineteeth century onwards. In these episcopal statements and pastoral or circular letters, the bishops sought to meet two objectives. First, they attempted to stem the influence of specific newspapers of which they disapproved and more generally, of the "bad press»; secondly, they tried to encourage the diffusion of "good" publications and the development of the Catholic press in general. The bishops' discourse seems to have been well-adapted to the circumstances, in that its authors showed an awareness of their adversaries' strength as well as the support they could expect from their congregation.

Dès la parution des premières gazettes, au début du Régime anglais, le clergé catholique a maille à partir avec les «ennemis» de la

1. Cet article a été rédigé grâce à une subvention du Conseil de recherches en sciences humaines du Canada, auquel nous exprimons notre reconnaissance. 
religion, disciples de Voltaire et propagateurs des Lumières². Toutefois, ces attaques sont le fait d'une poignée de francs-tireurs, et leur zèle anticlérical s'essouffle bientôt. Au XIX ${ }^{e}$ siècle, avec l'arrivée d'un grand nombre d'immigrants d'origine anglo-saxonne, un adversaire redouté, le protestantisme, s'introduit au sein de la catholicité québécoise. Des Églises nées de la Réforme s'installent dans la colonie; dès les années 1820 , elles lancent des revues et cherchent à séduire les Canadiens. Pendant ce temps, en Europe, les idéaux de liberté et d'égalité, emportés dans la fureur des années 1790 et longtemps refoulés par des gouvernements autoritaires, s'infiltrent dans les esprits et provoquent des sursauts révolutionnaires. À Montréal, de nouveaux journaux, L'Avenir et Le Pays, répercutent ces bouleversements et embouchent les trompettes de la liberté. Menacée sur plusieurs fronts, l'Église québécoise doit réagir et défendre ses positions. En 1840, après des années d'hésitation ${ }^{3}$, le premier journal catholique, les Mélanges religieux, est fondé à Montréal. De plus en plus sensibles aux effets néfastes de la propagande protestante et hostiles aux principes libéraux, les évêques s'en prennent publiquement à ces ennemis. Prise à partie, l'Église québécoise doit prendre parti: elle le fait par la bouche de ses évêques, dont nous allons ici faire le bilan du discours sur la presse, entre 1764 et 1914.

Même si peu de chercheurs se sont intéressés à l'attitude de l'Église catholique envers la presse au $\mathrm{XIX}^{\mathrm{e}}$ siècle ${ }^{4}$, plusieurs ont traité de ses prises de position sociopolitiques. Au risque d'exagérer les traits, nous pourrions dire que les historiens ont eu tendance à prendre des positions semblables à celles des protagonistes eux-mêmes. Soit que, convaincus de la légitimité de l'autorité épiscopale, ils trouvent justifiée l'attitude de l'Église à l'égard de la presse, soit, au contraire, qu'ils remettent en cause, en même temps que le magistère, la validité

2. Plusieurs auteurs ont abordé cette question. Nous ne signalons ici que quelques titres: Marcel Trudel, L'influence de Voltaire au Canada (Montréal, Fides, 1945), 2 vol.; Séraphin Marion, «Le voltairianisme de La Gazette littéraire de Montréal», Les lettres canadiennes d'autrefois (Ottawa, Éditions de l'Université d'Ottawa), 2: 29-88; Jean-Paul de Lagrave, Fleury Mesplet, diffuseur des Lumières au Québec (Montréal, Patenaude Éditeur, 1985); C. Rouben, «Les échos de la Révolution française dans la presse canadienne de 1789 à 1794: le voltairianisme de La Gazette de Montréal», L'Information historique, 50,5 (1988): 163-171. Voir, pour plus de détails, Jean de Bonville, dir., La presse québécoise de 1764 à 1914: bibliographie analytique (Sainte-Foy, Presses de l'Université Laval, 1995), 351 p.

3. Voir Thomas-M. Charland, «Un projet de journal ecclésiastique de Mgr Lartigue», Société canadienne d'histoire de l'Église catholique: rapport, 1956-1957, 39-53.

4. Séraphin Marion est un des premiers «universitaires» à se pencher sur le sujet. (Fonctionnaire aux Archives fédérales, il a enseigné la littérature canadienne à l'Université d'Ottawa de 1926 à 1952, et plusieurs de ses travaux ont été publiés aux Éditions de l'Université d'Ottawa). Si l'on fait exception de quelques mémoires et d'une poignée d'articles, ce thème demeure peu exploré. 
de son enseignement ${ }^{5}$. Ces tendances contradictoires, en plus de soulever la question de l'objectivité de l'historien, posent problème au développement d'une historiographie sur le sujet. Il nous semble nécessaire, pour surmonter cette contradiction idéologique, d'échapper à l'alternative qu'introduisent inéluctablement les concepts de légitimité et de validité. Plutôt que de considérer l'enseignement de l'Église, et plus particulièrement des évêques québécois, de ce point de vue, nous proposons d'analyser leur discours sous l'angle de sa rationalité. Cette proposition implique une problématique et une approche méthodologique particulières.

Dans la seconde moitié du XIX ${ }^{\mathrm{e}}$ siècle, l'Église québécoise est une institution sociale en progrès. À l'intérieur de l'Église, de fait aussi bien qu'en vertu de la théologie en vigueur à l'époque, le clergé constitue une élite; classe dirigeante au sein d'une institution qui accède au premier plan, il possède donc un statut social dominant, car le sort de l'Église et du clergé sont étroitement liés. Le statut social du clergé se renforce à mesure que s'accroît le rôle de l'Église catholique dans la société québécoise. Évêques et prêtres ont conscience de former un groupe choisi à l'intérieur d'une institution prédestinée. Or cette institution possède une doctrine, des règles, une hiérarchie, une tradition qui s'imposent au clergé québécois en même temps qu'elles l'instituent et le soutiennent. Dès lors que nous envisageons le discours du clergé québécois dans cette perspective, il n'est plus question de savoir s'il est légitime de s'opposer à la liberté de la presse ou de condamner un journal rouge, mais plutôt si ces attitudes sont rationnelles, c'est-à-dire si elles sont cohérentes avec la position sociale du clergé et la renforcent. Cette notion de rationalité n'est pas simple ${ }^{6}$ au

5. Voir à ce sujet Guy Laperrière, «L'évolution de l'histoire religieuse au Québec depuis 1945: le retour du pendule?», Érudition, humanisme et savoir: colloque en l'honneur de Jean Hamelin (Sainte-Foy, Presses de l'Université Laval, 1995), à paraître.

6. Selon Pareto, «une action est dite rationnelle lorsqu'elle est objectivement bien adaptée au but poursuivi par le sujet» (Raymond Boudon et François Bourricaud, Dictionnaire critique de la sociologie (Paris, Presses universitaires de France, 1994), 479). Voir l'ensemble de l'article «Rationalité, 479-487. Dans cette acception praxéologique, rationalité signifie adaptation des moyens aux fins. Dans le cas où plusieurs moyens sont disponibles et peuvent être ordonnés, l'action rationnelle est celle qui utilise le meilleur moyen en fonction du critère le plus pertinent. Selon la force ou la faiblesse de l'adversaire, le nombre et la qualité des alliés, la probabilité de gains ou de pertes, la solution rationnelle peut être l'affrontement, la coopération ou le compromis. La rationalité d'une action peut être évaluée à court et à long terme. Certaines initiatives, jugées rationnelles à court terme, peuvent s'avérer non rationnelles à long terme. En effet, les agents sociaux ne disposent que d'une quantité limitée d'informations concernant la situation et le résultat de leur action. D'autre part, l'écart entre les fins recherchées et les résultats obtenus dépend grandement de l'action d'autres agents sociaux, souvent antagonistes, et du jeu de facteurs imprévisibles ou à tout le moins imprévus, etc. Comme on peut le constater, la notion de rationalité n'est pas univoque, et il n'en peut exister une définition générale. «La notion de rationalité doit donc être conçue comme relative, c'est-à-dire comme dépendant de la structure 
contraire les évêques québécois peuvent être placés, à l'occasion, devant des choix dont la rationalité est contradictoire; par exemple, lorsqu'une décision ou une déclaration présente des avantages certains à court terme, mais douteux à long terme.

Cette manière d'aborder le sujet pose des exigences particulières à la démarche méthodologique. En effet, l'historien doit se mettre à la place de l'acteur lui-même afin de saisir la rationalité de son discours. Formule consacrée, cette proposition doit, ici, être prise au sérieux; car pour juger de la rationalité de l'attitude du clergé québécois à l'égard de la presse, il faut tenir compte des contraintes qui s'exercent sur lui aussi bien que des ressources dont il dispose pour s'opposer à ses adversaires ou s'attirer des alliés; il faut, de plus, connaître les rôles joués par les différents protagonistes, la nature des enjeux et les règles du jeu ${ }^{7}$. Nous nous proposons donc de décrire le discours officiel de l'Église québécoise sur la presse, mais nous voulons aussi le situer à l'intérieur des considérations qui s'imposent au clergé du XIX ${ }^{\mathrm{c}}$ siècle. En conséquence, nous commencerons par évoquer les droits et les devoirs de l'évêque et par décrire les conditions d'exercice de son autorité. Nous ferons aussi un rapide inventaire des moyens de communication dont il dispose pour faire entendre son discours. Nous procéderons ensuite à l'analyse thématique de ce discours et nous nous demanderons, enfin, dans quelle mesure celui-ci était adapté aux conditions de son émission et de sa réception.

\section{I - LA SOURCE DU DISCOURS: L'ÉVÊQUE}

L'Église catholique est une institution fortement hiérarchisée, dont l'autorité repose entre les mains d'un groupe restreint d'individus, les évêques. L'évêque de Rome, le pape, est investi de l'autorité suprême, et c'est à lui qu'il appartient de nommer les autres évêques ou, à tout le moins, de les instituer ${ }^{8}$. L'évêque possède des droits qui lui sont

des situations. Bien entendu, elle doit aussi être conçue comme dépendant de la position et généralement des caractéristiques des acteurs» (ibidem, 484). Le terme rationalité peut également s'appliquer à des énoncés explicatifs. Ceux-ci sont alors perçus comme rationnels s'ils sont congruents avec le savoir disponible sur le sujet au moment de la formulation de l'énoncé.

7. À propos de la rationalité des agents sociaux, il est bon de rappeler cette remarque: «lorsqu'un observateur interprète le comportement de l'observé comme irrationnel, cela résulte bien souvent de ce qu'il projette indûment les données caractéristiques de sa propre situation sur la situation de l'observé. Il aura alors tendance à interpréter le comportement de l'observé comme résultant d'une mystérieuse et irrationnelle 'résistance au changement', là où il s'agit d'un comportement rationnel par rapport à la situation de l'observé lui-même» (R. Boudon et F. Bourricaud, ibidem, 484).

8. Il ne serait pas pertinent d'entrer dans le détail de la nomination des évêques puisque, comme en Angleterre et aux États-Unis, les évêques québécois sont nommés directement par le pape, contrairement à ce qui se passait, au $\mathrm{XIX}^{\mathrm{e}}$ siècle, dans plusieurs pays européens dont les monarques avaient le privilège de nommer les évêques. 
réservés (confirmation des fidèles, consécration des églises, etc.) et d'autres qu'il peut déléguer (collation des ordres mineurs, bénédiction des cloches, etc.). La juridiction ordinaire de l'évêque s'exerce sur les fidèles et les clercs d'un territoire particulier, qui lui est assigné par le pape. De là découlent les obligations de résidence et de la visite pastorale. C'est de l'évêque que relève, en dernière instance, l'administration des biens matériels appartenant aux paroisses et aux autres institutions catholiques de son diocèse. L'évêque a la responsabilité de gouverner le diocèse, mais aussi d'instruire les fidèles. À l'intérieur de son diocèse, tous les catholiques, et plus particulièrement les clercs, lui sont soumis et doivent obéir aux règlements qu'il formule. À l'égard de la conduite, des opinions et des écrits des fidèles ou des clercs de son diocèse, l'évêque peut exercer son droit de censure. La notion de censure est générale et englobe les trois catégories suivantes 9 .

Les ouvrages qui abordent des questions de religion ou de morale sont soumis à la censure préventive ou préalable. Les auteurs, éditeurs ou imprimeurs doivent remettre à l'évêché tout manuscrit relevant de cette catégorie d'écrits. Des examinateurs, choisis dans le clergé local, lisent ces textes pour en vérifier la concordance avec la doctrine catholique et donnent leur avis sur ce sujet. S'il est favorable, il s'exprime par les mots «Nihil obstat»; dans ce cas, l'évêque accorde l' «imprimatur», c'est-à-dire la permission de publier l'ouvrage. Les membres du clergé doivent, même sur des questions profanes, soumettre leurs écrits à la censure préalable. Les journaux ou les revues sont aussi soumis à cette censure, et leurs éditeurs doivent transmettre à l'évêché, avant publication, les articles portant sur la religion ou la morale. Pour faciliter ce mécanisme, difficilement compatible avec les contraintes de la périodicité, l'évêque peut désigner comme censeur un rédacteur de la publication. C'est évidemment le cas dans les journaux dirigés par des clercs, journaux dont l'ensemble du contenu, et non pas seulement les textes sur la religion et la morale, doit être vérifié.

La censure préalable ne préjuge pas de la conformité des opinions puisqu'elle considère les écrits irréprochables aussi bien que les écrits condamnables, mais il n'en va pas de même de la censure doctrinale, prononcée a posteriori et impliquant un jugement négatif. Un livre, un périodique, une thèse ou une proposition sont alors blâmés parce que jugés contraires à la doctrine catholique. La sévérité de cette censure

9. En ce qui concerne la censure, voir les articles pertinents dans Catholicisme: hier, ajourd'hui, demain (Paris, Letouzey et Ané, 1947), 2: 797-803; A. Vacant et E. Mangenot, dir., Dictionnaire de théologie catholique (Paris, Letouzey et Ané, 1910), 2: 2101-2136; ${ }^{\mathrm{gr}}$ André et P. Condis, Dictionnaire de droit canonique (Paris, Hippolyte Walzer, 1889), 327-341. 
varie en fonction de l'intensité de l'opposition à la doctrine. Elle peut toucher la forme aussi bien que le fond de l'opinion condamnée ou encore viser les effets que son expression est susceptible de provoquer. La condamnation peut se limiter à une proposition ou à un ensemble de propositions, mais elle peut aussi frapper un ouvrage complet ou l'œuvre intégrale d'un auteur; dès lors, ceux-ci sont mis en entier à l'Index.

La censure pénale, enfin, est une peine ecclésiastique qui vise à forcer le coupable à s'amender. Certaines de ces peines, comme la suspense et l'interdit ${ }^{10}$, visent particulièrement les clercs, tandis que l'excommunication peut être lancée contre clercs ou laïcs. Comme il s'agit d'une peine d'une grande sévérité, l'excommunication doit être réservée aux cas où les fautes sont très graves, extérieures, c'est-à-dire connues des fidèles, et commises au mépris de l'autorité de l'Église, c'est-à-dire explicitement défendues sous peine de censure, soit par le droit (de jure), soit par l'évêque personnellement. Les censures comminatoires, c'est-à-dire consécutives à une défense expresse de l'évêque, ne sont valides que si la personne visée par la censure a fait l'objet de trois monitions personnelles et écrites. Peines médicinales visant le retour du fidèle à un état de santé spirituelle, ces censures ne concernent évidemment que les baptisés et ne peuvent être prononcées que par le pape ou un évêque. Elles peuvent être imposées pour un nombre limité de motifs ${ }^{11}$.

Pour instruire les fidèles de son diocèse, l'évêque dispose de plusieurs moyens. Il peut, évidemment, prêcher dans son église cathédrale, mais il doit aussi, régulièrement, se rendre dans les paroisses de son diocèse, en visite pastorale. Cependant, il ne peut rejoindre ainsi l'ensemble des fidèles aussi souvent qu'il le souhaiterait. Aussi a-t-il recours à d'autres moyens de communication comme les lettres pastorales, les mandements ou encore, s'il désire restreindre son public, les lettres circulaires au clergé. La lettre pastorale contient l'enseignement d'un évêque ou d'un groupe d'évêques sur la vie religieuse de l'Église locale ou sur des problèmes auxquels elle fait

10. L'interdit défend la célébration des offices divins à un clerc ou dans un lieu particulier. La suspense prive un clerc de ses bénéfices et, occasionnellement, de ses pouvoirs.

11. Leur énumération serait évidemment trop longue, mais nous mentionnerons quelques fautes susceptibles d'entraîner une censure de jure. Ainsi sont passibles d'excommunication les individus qui attaquent les biens de l'Église ainsi que ceux qui prêtent conseil à ces agresseurs, ceux qui exercent une violence physique contre des clercs ou des religieux, ceux qui contraignent ou induisent des juges laïcs à faire comparaître des clercs devant des tribunaux civils, ceux qui se battent en duel, ceux qui adhèrent à des sectes comme celle des francs-maçons, ceux qui impriment, lisent ou encore défendent des livres d'auteurs apostats ou d'autres œuvres défendues, etc. 
face. Comme la lettre encyclique pour le pape, la lettre pastorale est l'expression du magistère ordinaire de l'évêque. Souvent liée au rythme de l'année liturgique, la lettre pastorale accompagne fréquemment un mandement, lequel édicte des règles à suivre, ordonne, commande. À la différence de la lettre pastorale, qui n'est pas mentionnée dans le droit canon, le mandement est lié explicitement à la juridiction de l'évêque. La lettre circulaire, enfin, est un moyen pratique par lequel l'évêque se tient en relation avec ses principaux collaborateurs, les prêtres de son diocèse. Certaines de ces circulaires accompagnent les documents pontificaux, les lettres pastorales ou les mandements; elles contiennent alors des règles d'interprétation ou des directives sur la manière de communiquer aux fidèles ces documents. L'évêque utilise aussi ce moyen pour formuler des recommandations ou des directives au clergé sur ses activités pastorales, pour annoncer des événements particuliers comme une retraite ou les étapes de la visite pastorale, pour solliciter sa collaboration à des œuvres diocésaines, etc. À la fin du XIX ${ }^{\mathrm{e}}$ siècle, enfin, apparaissent, dans quelques diocèses, des périodiques dont le but est de tenir le clergé et les fidèles informés des activités religieuses du diocèse. C'est ainsi que, sous l'inspiration d'expériences françaises ${ }^{12}$, sont fondées, en 1883, $L a$ Semaine religieuse de Montréal et, en 1888, La Semaine religieuse de Québec. Bien que soumises à la censure préventive, ces revues ne sont pas pour autant des publications officielles de l'évêché.

En 1914, le Québec compte onze diocèses, mais, durant près des trois quarts de siècle suivant la Conquête, l'évêque de Québec a été le seul responsable de l'Église canadienne. Le diocèse de Montréal a été fondé en 1836, suivi par les diocèses de Saint-Hyacinthe et de TroisRivières, en 1852. L'ouverture de nouvelles régions ou la croissance démographique de régions déjà colonisées entraînent la création de nouveaux diocèses ${ }^{13}$. La région de l'Outaouais est rattachée au diocèse d'Ottawa. À partir de 1844, les diocèses canadiens forment une province ecclésiastique dont le chef est l'archevêque de Québec. En 1886, Montréal et Ottawa deviennent, à leur tour, les métropoles de deux nouveaux archidiocèses. Les évêques de Saint-Hyacinthe, de Sherbrooke et, plus tard, de Valleyfield et de Joliette sont les suffragants

12. Voir Émile Poulat, Les "Semaines religieuses»: approche socio-historique et bibliographique des Bulletins diocésains français (Lyon, Centre d'histoire du catholicisme, 1972), 1217.

13. Rimouski, en 1867; Sherbrooke, en 1874; Chicoutimi, en 1878; Nicolet, en 1885; Valleyfield, en 1892; et Joliette en 1904. Le diocèse de Mont-Laurier n'est érigé qu'en 1913 et occupe une partie du territoire des évêchés de Montréal et d'Ottawa. L'archidiocèse d'Ottawa comprend notamment, à partir de 1898 , le diocèse de Pembroke dont le territoire englobe une partie des diocèses de Montréal, de Trois-Rivières et d'Ottawa. 
de l'archevêque de Montréal, tandis que ceux de Trois-Rivières, Nicolet, Chicoutimi et Rimouski continuent de relever de l'archevêque de Québec.

\section{2 - LE DISCOURS DES ÉVÊQUES SUR LA PRESSE: INVENTAIRE SOMMAIRE}

Pour mesurer la place faite à la presse par les évêques québécois dans leurs communications officielles, nous avons fait l'inventaire des lettres pastorales, des mandements et des circulaires ${ }^{14}$. Ces documents forment un corpus volumineux. Les textes provenant des seuls diocèses de Québec et de Montréal occupent près de 14000 pages $^{15}$. Ceux-ci contiennent, il est vrai, des documents pontificaux, dans une proportion de $10 \%$ environ du nombre total de documents. Les lettres pastorales et les mandements représentent aussi, respectivement, $10 \%$ du corpus, tandis que les circulaires sont les documents les plus nombreux, avec plus de $40 \%$ du total. Les autres documents (avis divers, listes, etc.) représentent un peu moins de $30 \%$ des textes. Lorsqu'ils étaient pertinents, nous avons aussi tenu compte de ces autres documents. Nous avons, tout d'abord, réparti le contenu des documents provenant des diocèses de Québec et de Montréal à l'intérieur d'une grille thématique dont les neuf catégories représentent les domaines dans lesquels les évêques interviennent plus ou moins fréquemment. La plupart des documents ont fait l'objet d'une catégorisation unique, mais les documents comprenant plusieurs sections sur des thèmes particuliers ont été dénombrés sous chacun des thèmes pertinents ${ }^{16}$ (tableaux 1 et 2).

14. Le dépouillement des séries documentaires a été fait par une auxiliaire de recherche, Renée Gagnon, que nous remercions vivement de sa précieuse collaboration.

15. La publication de ces documents est souvent fort postérieure à leur diffusion, et les critères de sélection qui ont guidé les différents éditeurs des recueils ne nous sont pas connus. Cependant, il semble qu'ils aient eu le souci d'imprimer tous les documents qui possédaient un caractère universel selon l'Église diocésaine. Ils auraient ainsi écarté une partie de la correspondance destinée à des clercs individuels, à des paroisses particulières, etc. Toutefois, même s'il n'est pas facile de mesurer l'exhaustivité des recueils quant aux textes à caractère universel, il semble que tous les documents importants aient été imprimés. Les éditeurs ont euxmêmes détecté des oublis et publié ultérieurement des textes omis dans des volumes précédents. De plus, il est probable que les critères de sélection ont varié d'un diocèse à l'autre et, sans doute, dans le temps à l'intérieur d'un même diocèse. La mesure de l'exhaustivité de cette source dépassait évidemment les objectifs de notre recherche. Quoi qu'il en soit, les responsables des archives en question confirment la quasi-exhaustivité des recueils en ce qui concerne les textes destinés à toute la communauté diocésaine.

16. La catégorie Religion comprend les documents relatifs à la pratique religieuse (ex.: jeûne, indulgences, liturgie, etc.), aux questions théologiques (ex.: dogme de l'Immaculée Conception), à l'administration des biens de l'Église (ex.: tenue des registres, achats, comptes de la fabrique, etc.), les œuvres de la Propagation de la foi, etc. La catégorie Politique comprend 
Tableau 1

Thèmes des communications officielles de l'évêque de Québec de 1764 à 1914 (en pourcentage de la fréquence)

\begin{tabular}{|c|c|c|c|c|c|c|c|c|c|c|}
\hline & Religion & Politique & Société & Économie & Éducation & Catastrophes & Culture & Presse & Autres & Total \\
\hline $\begin{array}{l}1760 \\
1779\end{array}$ & 49 & $\begin{array}{lll}43,1 & & \\
& 9,6\end{array}$ & 2,0 & & & 5,9 & & & & 100 \\
\hline $\begin{array}{l}1780 \\
1799\end{array}$ & 61,8 & 26,3 & 6.7 & & 3,9 & 1,3 & & & & 100 \\
\hline $\begin{array}{l}1800 \\
1819\end{array}$ & 47,6 & 15,7 & 1,0 & 3,7 & & 3,7 & & & & 100 \\
\hline $\begin{array}{l}1820 \\
1839\end{array}$ & 3,5 & 7,4 & 12,8 & & 3,9 & 1,4 & & & & 100 \\
\hline $\begin{array}{l}1840 \\
1859\end{array}$ & 11,7 & 10,8 & 13,1 & 10,8 & 2,4 & 13,5 & $\begin{array}{|ll|}4,8 & \\
& 16,9\end{array}$ & 2,9 & 1,4 & 100 \\
\hline $\begin{array}{l}1860 \\
1879\end{array}$ & 71,7 & 23 & 18,2 & 3,5 & 15,7 & 32,5 & $\begin{array}{|ll|}1,8 & \\
& 13,6\end{array}$ & $\begin{array}{ll}2,4 & \\
& 31,4\end{array}$ & 0,4 & 100 \\
\hline $\begin{array}{l}1880 \\
1899\end{array}$ & 67,3 & 15,2 & 39,4 & 51,7 & 58,8 & 10,8 & $\begin{array}{|ll|}5,1 & \\
& 47,5\end{array}$ & $\begin{array}{lll}1,8 & \\
& 28,6\end{array}$ & 0,9 & 100 \\
\hline $\begin{array}{l}1900 \\
1914\end{array}$ & 15,2 & 9,6 & 13,1 & 0,8 & 1,2 & 21,6 & 5,3 & 3,3 & & 100 \\
\hline $\begin{array}{c}\text { Total } \\
\text { N:1735 }\end{array}$ & 100 & 100 & 100 & 100 & 100 & 100 & 100 & 2,0 & 100 & 100 \\
\hline
\end{tabular}


Tableau 2

Thèmes des communications officielles de l'évêque de Montréal de 1836 à 1914 (en pourcentage de la fréquence)

\begin{tabular}{|c|c|c|c|c|c|c|c|c|c|c|}
\hline & Religion & Politique & Société & Économie & Éducation & Catastrophes & Culture & Presse & Autres & Total \\
\hline $\begin{array}{l}1836 \\
1839\end{array}$ & $\begin{array}{lll}64 & \\
& 1,2\end{array}$ & 28 & & & 1,4 & 2,7 & & & & 100 \\
\hline 1840 & 61,8 & 6,6 & 12,8 & 5,2 & 4,8 & 1,3 & 5,1 & 1,3 & 1,1 & 100 \\
\hline 1859 & 24,4 & 13 & 39,2 & 31,5 & 35,6 & 18,9 & 23,3 & 20 & 31,6 & 24,7 \\
\hline 1860 & 59,6 & 18,7 & 7,2 & 3,7 & 1,8 & 2,1 & 4,5 & 1,7 & 0,7 & 100 \\
\hline 1879 & 33,5 & 53,2 & 31,3 & 31,5 & 19,1 & 43,3 & 28,4 & 37,2 & 26,4 & 35,1 \\
\hline 1880 & 64,2 & 10,4 & 5,5 & 4,3 & 5,1 & 1,4 & 6,4 & 1,5 & 1,2 & 100 \\
\hline 1899 & 28,6 & 23,8 & 19,3 & 29,2 & 42,5 & 24,3 & 33,6 & 25,7 & 36,8 & 27,5 \\
\hline 1900 & 69,3 & 8,3 & 7,5 & 2,9 & 0,4 & 1,7 & 7 & 2,5 & 0,4 & 100 \\
\hline 1914 & 12,3 & 7,4 & 10,2 & 7,8 & 1,4 & 10,8 & 14,7 & 17,1 & 5,2 & 11,1 \\
\hline Total & 62,5 & 12,4 & 8,1 & 4,1 & 3,4 & 1,7 & 5,4 & 1,6 & 0,8 & 100 \\
\hline $\mathrm{N}: 2173$ & 100 & 100 & 100 & 100 & 100 & 100 & 100 & 100 & 100 & 100 \\
\hline
\end{tabular}


L'année 1840 semble marquer une changement de régime dans la communication des évêques avec leur peuple. Avant cette date, l'évêque ne s'adresse que rarement par voie écrite aux fidèles et même au clergé. Entre 1760 et 1839, le nombre moyen de correspondances est inférieur à 4 par année (nous tenons compte de tous les types de documents dans ce calcul). Dès les années 1840 à 1859, le seul évêque de Québec adresse une dizaine de lettres ou mandements par année à ses diocésains. Durant la même période, l'évêque de Montréal, plus prolifique, leur en transmet en moyenne 27 par année. Ces chiffres sont les indices non équivoques d'une communication plus soutenue, mais ils laissent deviner, surtout à Montréal, la présence plus active de l'évêque auprès de ses ouailles et, sans doute, un souci plus grand de normalisation et de contrôle de la vie de l'Église locale ${ }^{17}$. Au fil des décennies, les évêques ont même tendance à accroître encore la fréquence de leurs correspondances, à tout le moins jusqu'au début du $\mathrm{XX}^{\mathrm{e}}$ siècle, puisqu'à partir de ce moment le rythme des communications diminue sensiblement, à savoir de plus de $40 \%$ dans chacun des deux diocèses.

Si l'on se fie à l'éventail des thèmes abordés dans leur correspondance officielle, les évêques de Québec et de Montréal se préoccupent surtout, comme il est prévisible, de questions religieuses; ils y consacrent, en effet, $64 \%$ de leurs textes. Chacun des autres thèmes demeure d'importance négligeable même si, réunis, ils occupent plus de $35 \%$ des communications. Durant les premières décennies du Régime anglais et même jusqu'à l'Acte d'Union, les questions politiques occupent une place importante parmi les lettres de l'évêque de Québec, au demeurant peu nombreuses. Durant les années 1860 et 1870 , les querelles qui opposent les rouges aux ultramontains stimulent l'intérêt pour ces questions, si bien que 39\% des écrits portant sur la politique datent de ces deux décennies. Pourtant, l'importance de ce

\footnotetext{
des documents sur les élections, l'attitude à adopter à l'égard de l'Angleterre, son gouvernement et son monarque, les questions politico-religieuses. La catégorie Économie comprend les documents concernant l'agriculture, les sociétés d'ouvriers, la monnaie, etc. La catégorie Société comprend les documents dénonçant certains problèmes sociaux (ex.: alcoolisme, prostitution) ainsi que les solutions proposées pour régler ces problèmes (ex.: fondation d'orphelinats, d'asiles pour les pauvres, etc.); cette catégorie comprend aussi les documents portant sur la santé (ex.: questions d'hygiène, fondation d'hôpitaux, épidémies, conseils aux médecins, etc.). La catégorie Catastrophes comprend les documents traitant de catastrophes naturelles (ex.: inondations, sécheresses, etc.) et accidentelles (ex.: incendie); les documents concernant les mauvaises récoltes sont classés dans la catégorie Économie. La catégorie Culture comprend les documents portant sur le livre et autres publications non périodiques, sur la danse sociale, le théâtre, le cinéma, la mode et les loisirs. Les pourcentages sont établis sur la fréquence des thèmes et non sur la surface qui leur est consacrée dans les documents.

17. Manifestation de cette volonté de normalisation, le rapport paroissial que les curés doivent faire parvenir à leur évêque, chaque année, à partir du milieu des années 1850 .
} 
thème décline sensiblement au fil des années. Les questions culturelles sont pratiquement absentes des communications des évêques jusque dans les années 1840 et, par la suite, elles demeurent secondaires, ne se méritant qu'environ $4 \%$ des textes. De ce nombre, plus de la moitié portent sur la littérature, c'est-à-dire sur les mauvais livres qu'il faut bannir des foyers catholiques et sur les bonnes lectures qu'il importe, au contraire, d'encourager. Bien qu'elle fasse logiquement partie du domaine culturel, nous en avons mis à part la presse à des fins analytiques. Celle-ci est le thème de moins de $2 \%$ des documents, et l'intérêt des évêques pour ce sujet demeure relativement stable à partir du milieu du XIX ${ }^{\mathrm{e}}$ siècle.

Nous avons élargi notre analyse à l'ensemble des diocèses dont le siège épiscopal est situé au Québec ${ }^{18}$. En revanche, nous avons resserré nos critères de sélection de manière à ne retenir que les documents consacrés entièrement à la presse ou dont une section, identifiée par un titre ou numéro distinctif, traitait exclusivement de ce sujet. Nous avons ainsi repéré 90 textes, dont 45 portent intégralement sur la presse. Un peu plus de la moitié sont des circulaires au clergé, un cinquième sont des pastorales individuelles ou collectives, tandis que les mandements et les autres documents représentent respectivement environ 17 et $6 \%$ de ce corpus ${ }^{19}$.

Nous avons réparti les documents portant sur la presse à l'intérieur de six thèmes abordés par les évêques. En effet, ces derniers considèrent tantôt des publications particulières, tantôt la presse dans son ensemble. S'il leur arrive souvent de réprimander et de condamner, il n'est pas rare non plus de lire des encouragements à la «bonne presse» ou à des publications recommandables. Ils se préoccupent, enfin, de la manière dont les journalistes catholiques remplissent leur importante mission. Ces modalités du discours des évêques nous ont donc servi à classer par catégories les documents sélectionnés (tableau 3).

Le nombre de textes sur la presse augmente progressivement pour atteindre un sommet dans les années 1880. Par la suite, les évêques reviennent moins souvent sur le sujet, à l'exception du début de la décennie 1910. Durant un intervalle de moins de trois ans, douze

18. À l'exception d'une pastorale, en 1883 , la correspondance officielle des évêques d'Ottawa contient peu de docurnents originaux sur la presse. Nous n'en avons pas tenu compte dans notre analyse.

19. Les proportions précises de ces différentes catégories sont les suivantes. Circulaires entières: $25,9 \%$; circulaires partielles: $31,5 \%$; lettres pastorales entières: $10,1 \%$; lettres pastorales partielles: $10,1 \%$; mandements entiers: $11,2 \%$; mandements partiels: $5,6 \%$; autres documents entiers: $3,4 \%$; autres documents partiels: $2,2 \%$. 
Tableau 3

Thèmes des communications officielles des évêques québécois sur la presse, par décennie, de 1849 à 1914 (nombre de communications)

\begin{tabular}{|c|c|c|c|c|c|c|c|c|c|}
\hline & & $\begin{array}{l}\text { Droits et } \\
\text { devoirs }\end{array}$ & $\begin{array}{c}\text { Appui a } \\
\text { publication }\end{array}$ & $\begin{array}{c}\text { Soutien presse } \\
\text { catholique }\end{array}$ & $\begin{array}{c}\text { Avertissement } \\
\text { publication }\end{array}$ & $\begin{array}{c}\text { Condamnation } \\
\text { mauvaise presse }\end{array}$ & Autres & \multicolumn{2}{|c|}{ Total } \\
\hline $1849 / 1859$ & & & 5 & & & 3 & & 8 & 8,9 \\
\hline $1860 / 1869$ & & & 1 & & 2 & 2 & & 5 & 5,6 \\
\hline $1870 / 1879$ & & 4 & 2 & & 9 & & 1 & 16 & 17,7 \\
\hline $1880 / 1889$ & & 8 & 3 & 1 & 11 & & 1 & 24 & 26,7 \\
\hline $1890 / 1899$ & & 3 & 1 & & 6 & 2 & 2 & 14 & 15,6 \\
\hline $1900 / 1909$ & & 1 & & 5 & 4 & & 1 & 11 & 12,2 \\
\hline $1910 / 1914$ & & & 3 & 1 & 8 & & & 12 & 13,3 \\
\hline Total & $\begin{array}{l}\text { N: } \\
\text { \%: }\end{array}$ & $\begin{array}{c}16 \\
17,7\end{array}$ & $\begin{array}{c}15 \\
16,7\end{array}$ & $\begin{array}{c}7 \\
7,8\end{array}$ & $\begin{array}{c}39 \\
43,3\end{array}$ & $\begin{array}{c}8 \\
8,9\end{array}$ & $\begin{array}{c}5 \\
5,6\end{array}$ & 90 & 100 \\
\hline
\end{tabular}


textes sont alors publiés, mais, de ce nombre, six concernent Le Pays, condamné simultanément par plusieurs évêques. Les communications des évêques se distribuent dans trois catégories principales: d'abord des avertissements ou des condamnations, puis les questions relatives aux droits et devoirs de la presse ou des journalistes et, dans des proportions comparables, les demandes d'appui à des publications recommandables. Dans ces trois catégories de textes, le taux de redondance est assez élevé. En effet, il n'est pas rare que plusieurs évêques fassent écho à une condamnation prononcée par l'un d'eux. Ainsi, les 39 documents classés sous le thème «Avertissement à une publication» ne concernent que 20 titres différents; ce qui veut dire que près de la moitié de ces textes ne sont que des répétitions. C'est le cas aussi, mais dans une moindre mesure, des 15 textes de recommandation, qui visent 11 titres différents. Les textes portant sur les droits et devoirs des journalistes sont souvent des décrets de conciles provinciaux, dont le cinquième, en 1873 , et le septième, en 1886 , traitent de la question. Ainsi, en 1886, cinq documents épiscopaux (imprimés dans des recueils parus en 1889) rapportent ou commentent le même décret XXII sur les journalistes catholiques. Certains documents, provenant d'un même évêque, sont, à l'occasion, liés entre eux. C'est le cas, par exemple, d'une circulaire au clergé dans laquelle l'évêque explique la manière dont il souhaite voir les curés présenter aux fidèles un mandement condamnant un journal ${ }^{20}$. Enfin, autre exemple de redondance, les rappels que font les évêques de décisions déjà prises, de condamnations déjà prononcées, etc. Si nous écartions ces documents redondants, il ne nous resterait plus qu'une soixantaine de textes.

Les textes portant sur des publications particulières, soit pour les recommander, soit pour les réprimander, se distribuent assez régulièrement de 1849 à 1914 . Le premier document consacré entièrement à la presse est d'ailleurs une circulaire de $\mathrm{M}^{\mathrm{gr}}$ Signay, datée du 15 octobre 1849 , dans laquelle le prélat demande aux prêtres de son diocèse d'encourager leurs paroissiens à s'abonner à un périodique agricole $^{21}$. Par la suite, les évêques sollicitent l'appui du clergé et des fidèles surtout en faveur de publications religieuses (True Witness,

20. Par exemple, $\mathrm{M}^{\mathrm{gr}}$ Bourget écrit, en 1860: «À cette fin, nous notons des faits et nous reproduisons des écrits qui seraient peut-être déplacés dans un Mandement public, mais qui peuvent se trouver sans inconvénient dans un document privé» («Premier supplément au mandement du 31 mai 1860, concernant les journaux qui ont attaqué la Bulle de sa sainteté Pie IX, excommuniant les envahisseurs des États pontificaux, et autres», Mandements, lettres pastorales et circulaires des évêques de Montréal, 8 (1887): 208.

21. «Circulaire à messieurs les curés», Mandements, lettres pastorales et circulaires des évêques de Québec, 3 (1888): 556-557. 
Gazette des familles ou Semaine religieuse) et de journaux catholiques (Le Courrier du Canada, Le Nouveau Monde, L'Action sociale et Le Bien public ${ }^{22}$ ). Le premier de la vingtaine de journaux à subir une réprimande officielle de la part d'un évêque est Le Pays, en 1860. De ce nombre, six titres pourraient se ranger parmi les publications amies: l'évêque manifeste alors son mécontentement au sujet de la manière dont sont traitées les questions religieuses. En incluant Le Pays, douze journaux rouges ou libéraux sont l'objet de mises en garde ou de condamnations officielles de la part d'un ou de plusieurs évêques ${ }^{23}$. Les autres titres condamnés sont le quotidien protestant Witness et le journal américain Le Courrier des Etats-Unis.

En revanche, les questions générales, relatives soit à la bonne ou à la mauvaise presse, soit aux normes applicables au journalisme, sont abordées moins régulièrement par les évêques. Ainsi, sauf un document d'intérêt secondaire, tous les textes sur l'importance d'appuyer la presse catholique datent du début $\mathrm{du} \mathrm{XX}^{\mathrm{e}}$ siècle, tandis que les ravages de la mauvaise presse semblent préoccuper les évêques davantage dans les années 1850 et 1860 que par la suite. Enfin, l'essentiel des textes sur les droits et devoirs des journalistes date de 1873 et de 1886.

Les documents sur la presse proviennent de neuf diocèses différents ${ }^{24}$, mais, en réalité, cette question ne préoccupe réellement l'Église locale que dans trois diocèses: ceux de Montréal, de Québec et, dans une moindre mesure, de Trois-Rivières. La nature des communications épiscopales témoigne aussi bien de la situation de la presse à l'intérieur du diocèse que de l'attitude de l'évêque à son égard. Ainsi, $77 \%$ des communications des évêques de Montréal tombent dans la catégorie des réprimandes ou condamnations de publi-

22. On pourrait s'étonner de ne pas trouver mention des Mélanges religieux. De fait, ce périodique ne fait l'objet, sauf erreur, que d'une rapide allusion dans une circulaire consacrée à différents sujets et datée du 21 décembre 1840. «J'ai le plaisir de vous apprendre, y lit-on, que la présente Circulaire est le premier ouvrage sorti de la presse Ecclésiastique que l'on s'est procurée pour l'impression des Mélanges Religieux. Je vous prie de nouveau de vouloir bien favoriser cette publication, qui est toute entière dans les intérêts de la Religion, comme vous n'en doutez pas» («Circulaire à messieurs les curés, missionnaires et autres prêtres du diocèse de Montréal», Mandements, lettres pastorales et circulaires des évêques de Montréal, 1 (1869): 113).

23. Le Pays (1860 et 1871), Le Réveil (1876), La Sentinelle (1886), la réédition de La Lanterne (1886), Canada-Revue et L'Écho des Deux-Montagnes (1892), L'Électeur (1896), Les Débats (1903 et 1904), La Semaine (1909), La Vigie et Le Soleil (1911), La Lumière (1912) et Le Pays (1912 et 1913).

24. Nous n'avons repéré aucun document officiel provenant du diocèse de Chicoutimi. Toutefois, il faut noter que les évêques de Chicoutimi ont à l'occasion cosigné des documents collectifs, notamment la pastorale sur l'éducation (1894) et celle condamnant L'Électeur (1896). 
cations; elles constituent $45 \%$ de tous les textes de cette catégorie. En outre, sur les 22 communications des autres évêques québécois, près de la moitié sont des échos à des condamnations déjà prononcées par l'évêque de Montréal. Abstraction faite de ces derniers documents, c'est près des trois quarts des condamnations et avertissements qui seraient prononcées par les évêques de Montréal. Évidemment, cette disproportion s'explique par la concentration à Montréal de la majorité des périodiques québécois. Cependant, cette explication n'est pas suffisante, car, en contrepartie, les évêques de Montréal recommandent les bonnes publications et encouragent la presse catholique moins souvent que les évêques de Québec et de Trois-Rivières. De même, ils traitent moins souvent que ces derniers des devoirs des journalistes. En revanche, les textes de soutien à la presse catholique proviennent, pour l'essentiel, des seuls évêques de Québec et de Trois-Rivières; l'autre texte sur le sujet n'est qu'un encouragement poli de $\mathrm{M}^{\mathrm{gr}}$ Bruchési à L'Action sociale, que vient de lancer $\mathrm{M}^{\mathrm{gr}}$ Bégin (tableau 4).

\section{3 - LES ÉVÊQUES ET LA PRESSE:}

\section{INITIATIVES INDIVIDUELLES OU STRATÉGIE?}

Même si la presse n'apparaît pas comme une préoccupation majeure des évêques québécois, elle ne cesse, à partir du milieu du $\mathrm{XIX}^{\mathrm{e}}$ siècle, d'être présente à leur esprit. Cependant, les seules données numériques ne suffisent pas à rendre toutes les nuances de la position de l'épiscopat québécois sur ce sujet. Les évêques se révèlentils, conformément à une perception répandue dans l'historiographie, des censeurs compulsifs? Manifestent-ils une tendance autocratique excessive? Leurs condamnations sont-elles autant d'abus de pouvoir? Sont-ils, au contraire, hésitants et timorés? Se limitent-ils à réagir individuellement aux problèmes que leur causent journaux et journalistes ou se concertent-ils pour deviser de positions communes? Les seules communications officielles ne nous permettront pas de donner une réponse satisfaisante à toutes ces questions. Il faudra, en effet, pousser plus loin la recherche: dépouiller la correspondance des évêques, analyser le contenu des publications condamnées pour évaluer le degré de sévérité des évêques, etc. Toutefois, les textes à notre disposition contiennent assurément des indices révélateurs de l'attitude de l’Église québécoise envers la presse.

Le discours de l'épiscopat à l'égard de la presse révèle trois modalités qui nous serviront à en construire une typologie. La première modalité concerne le genre de problèmes auxquels font face les évêques ou encore le genre d'objectifs qu'ils se proposent d'atteindre. En effet, problèmes et objectifs sont tantôt particuliers, par exemple 


\section{Tableau 4}

Thèmes des communications officielles des évêques québécois sur la presse, par diocèse, de 1849 à 1914 (nombre de communications)

\begin{tabular}{|c|c|c|c|c|c|c|c|c|}
\hline & $\begin{array}{l}\text { Droits et } \\
\text { devoirs }\end{array}$ & $\begin{array}{l}\text { Appui a } \\
\text { publication }\end{array}$ & $\begin{array}{c}\text { Soutien presse } \\
\text { catholique }\end{array}$ & $\begin{array}{c}\text { Avertissement } \\
\text { publication }\end{array}$ & $\begin{array}{l}\text { Condamnation } \\
\text { mauvaise presse }\end{array}$ & Autres & N & $\%$ \\
\hline Québec & 3 & 6 & 2 & 6 & 1 & 1 & 19 & 21,1 \\
\hline Montréal & 1 & 2 & 1 & 17 & 1 & & 22 & 24,3 \\
\hline Saint-Hyacinthe & 3 & 1 & & 2 & 2 & & 8 & 8,9 \\
\hline Trois-Rivières & 4 & 3 & 4 & 2 & & 1 & 14 & 15,6 \\
\hline Rimouski & & 1 & & 1 & & 1 & 3 & 3,3 \\
\hline Sherbrooke & 1 & & & 4 & & & 5 & 5,6 \\
\hline Nicolet & & & & 3 & & 2 & 5 & 5,6 \\
\hline Valleyfield & & & & 1 & & & 1 & 1,1 \\
\hline Joliette & & & & 1 & & & 1 & 1,1 \\
\hline Documents collectifs & 4 & 2 & & 2 & 4 & & 12 & 13,3 \\
\hline $\begin{array}{l}\mathrm{N}: \\
\mathrm{q}:\end{array}$ & $\begin{array}{c}16 \\
17,7\end{array}$ & $\begin{array}{c}15 \\
16,7\end{array}$ & $\begin{array}{c}7 \\
7,8\end{array}$ & $\begin{array}{c}39 \\
43,3\end{array}$ & $\begin{array}{c}8 \\
8,9\end{array}$ & $\begin{array}{c}5 \\
5,6\end{array}$ & 90 & 100 \\
\hline
\end{tabular}


lorsqu'un journal rouge attaque le clergé ou qu'un évêque souhaite la fondation d'une feuille catholique, tantôt généraux, lorsque c'est toute la presse qui semble constituer un danger pour la religion ou encore lorsque la gravité de la situation exige une solution globale. La seconde modalité porte sur la nature de l'action des évêques. Ceux-ci réagissent à l'initiative de leurs adversaires ou encore prennent euxmêmes l'initiative de l'action. La dernière modalité est relative à la concertation à l'intérieur de l'épiscopat dont le discours révèle une réaction ou une initiative qui peuvent être soit individuelles, soit collectives. En croisant ces trois modalités, nous obtenons huit types de discours caractéristiques du comportement des évêques à l'égard de la presse (tableau 5).

S'il faut se fier à leurs publications officielles, le comportement des évêques à l'endroit de la presse est assurément de type réactif. $\mathrm{La}$ plupart du temps, l'évêque réagit individuellement à une difficulté particulière. De $\mathrm{M}^{\mathrm{gr}}$ Bourget, qui stigmatise Le Pays en 1860 , à $\mathrm{M}^{\mathrm{gr}}$ Bruchési, qui condamne une autre publication portant le même titre en 1913, ce comportement constitue sans doute la caractéristique modale. Avec la multiplication des diocèses, les évêques sentent le besoin de la concertation. Les réactions communes, comme la condamnation collective de Canada-Revue par l'archevêque de Québec et ses suffragants, demeurent rares, mais les réactions individuelles à un problème commun, comme l'illustrent, en 1882, les condamnations individuelles du Courrier des États-Unis par la plupart des évêques, deviennent plus fréquentes à partir des années 1890 . Les réactions à un problème général sont aussi une constante dans le discours épiscopal. À plusieurs occasions, les évêques réunis en concile provincial dénoncent la plaie des mauvais journaux ${ }^{25}$. Il arrive, à l'occasion, qu'un prélat s'en prenne individuellement à de tels problèmes. Les textes les plus significatifs, à cet égard, sont les pastorales de $\mathrm{M}^{\mathrm{gr}}$ Bourget, en 1858, et de $\mathrm{M}^{\mathrm{gr}}$ Taschereau, en 1892, sur les mauvais journaux ${ }^{26}$.

25. C'est le cas notamment dans la «Lettre pastorale des évêques de la province ecclésiastique de Québec réunis en assemblée à Montréal», en 1850 (Mandements, lettres pastorales et circulaires des évêques de M'ontréal, 3 (1887): 64-86); dans «Lettre pastorale des Pères du quatrième concile provincial de Québec», en 1868 (Mandements, lettres pastorales et circulaires des évêques de Montréal, 5 (1887): 319-345); et «Lettre pastorale des Pères du premier concile provincial de Montréal sur la presse», en 1895 (Mandements, lettres pastorales et circulaires des évêques de Montréal, 12 (1907): 131-167).

26. «Lettre pastorale de $\mathrm{M}^{\mathrm{gr}}$ l'Évêque de Montréal contre les mauvais journaux», Mandements, lettres pastorales et circulaires des évêques de Montréal, 3 (1869): 380-411; «Lettre pastorale au sujet de la vente de mauvais journaux», Mandements, lettres pastorales et circulaires des évêques de Québec, 7 (1892): 281-286. Les deux prélats offrent des définitions fort différentes de ce que sont les mauvais journaux, reflétant en cela la situation de la presse à leur époque respective. 
Tableau 5

Typologie du discours de l'épiscopat à l'égard de la presse

\begin{tabular}{|c|c|c|c|c|}
\hline \multirow{2}{*}{$\begin{array}{c}\text { Problème ou } \\
\text { objectif }\end{array}$} & Individuelle & Collective & Individuelle & Collective \\
\cline { 2 - 5 } & RiG & RcG & IiG & IcG \\
\hline Général & RiP & RcP & IiP & IcP \\
\hline Particulier & &
\end{tabular}

Bien que moins fréquents, les comportements de type actif ne sont pas rares. En effet, dès les années 1850 , les évêques prennent des initiatives en faveur des bons journaux. Ce sont la plupart du temps des gestes individuels à l'égard des projets particuliers, comme la fondation du Courrier du Canada ou du Nouveau Monde ${ }^{27}$. Il est plus rare que des évêques se concertent pour encourager un journal comme ils le font en 1854, en faveur du True Witness ${ }^{28}$. Le premier prélat à proposer une véritable stratégie à l'égard de la presse est $\mathrm{M}^{\mathrm{gr}}$ Bégin en 1907, dans sa pastorale sur l'action catholique. Son suffragant, $\mathrm{M}^{\mathrm{gr}}$ Cloutier, lui fait écho dans une pastorale de $1914^{29}$. Cependant, les communications officielles des évêques ne contiennent aucun indice d'une stratégie collective inspirée par ces deux documents. En effet, les autres évêques se contentent d'appuyer le projet de $\mathrm{M}^{\mathrm{gr}}$ Bégin.

D'entrée de jeu, nous avons proposé de considérer le discours épiscopal sous l'angle de sa rationalité. En l'occurrence, le problème est de savoir si le discours du clergé est adapté aux objectifs qu'il poursuit et aux ressources dont il dispose pour les atteindre. Les évêques cherchent d'abord à rendre le comportement des fidèles conforme aux prescriptions morales et dogmatiques de l'Église; en outre, ils veulent que, des points de vue moral et doctrinal, la société civile soit soumise à l'autorité ecclésiastique ${ }^{30}$. Les évêques font

27. «Circulaire aux présidents des Conférences ecclésiastiques du diocèse en faveur du Courrier du Canada», Mandements, lettres pastorales et circulaires des évêques de Québec, 4 (1888): 323-324; "Circulaire au clergé concernant Le Nouveau Monde», Mandements, lettres pastorales et circulaires des évêques de Montréal, 6 (1887): 249-254.

28. "Lettre circulaire des Pères du second concile provincial de Québec», Mandements, lettres pastorales et circulaires des évêques de Montréal, 2 (1869): 462-463.

29. «Lettre pastorale de Monseigneur Louis-Nazaire Bégin, archevêque de Québec, sur l'Action sociale catholique et en particulier sur l'Euvre de la presse catholique», Mandements, lettres pastorales et circulaires des évêques de Québec, 10 (1906): 57-69; "La presse catholique», Ma.ndements des évêques des Trois-Rivières, 8 (1909-1914): 537-550.

30 Malgré cette réserve, les points de friction demeurent nombreux, car la doctrine catholique embrasse de larges pans de la vie sociale comme le mariage et la vie familiale, l'enseignement, l'activité politique du clergé, etc. 
consensus à propos du premier objectif. Mais au sujet du second, leur conviction n'est pas égale; d'autre part, le passage des ans est susceptible d'altérer leur conception des rapports entre les pouvoirs civil et religieux. La principale ressource que l'épiscopat peut mettre au service de ces objectifs est d'ordre symbolique: il s'agit essentiellement de son pouvoir, c'est-à-dire de son autorité sur les fidèles catholiques, d'une part, et de son ascendant sur les autres détenteurs de pouvoir, particulièrement les détenteurs du pouvoir politique. Évidemment, les Églises locales ne sont pas dépourvues de ressources matérielles, mais celles-ci demeurent subsidiaires.

Pour être rationnelle, la position de l'Église québécoise à l'endroit de la presse doit donc tenir compte des ressources que l'épiscopat québécois peut mettre au service de sa vision du monde. Il y a donc lieu de se demander si les différents types de comportements envers la presse, auxquels font écho les communications épiscopales, sont en accord avec la situation des évêques québécois dans l'Église universelle, d'une part, et de l'Église locale dans la société québécoise, d'autre part. À cet égard, voici comment il est possible d'interpréter ce discours.

Au milieu du $\mathrm{XIX}^{\mathrm{c}}$ siècle, l'Église romaine est en butte à de multiples difficultés. Attaquée dans son pouvoir temporel par des puissances politiques rivales, minée en son sein par le libéralisme catholique, elle est sur la défensive et réagit en condamnant ses adversaires dans leur personne et leurs opinions. Les prélats québécois, celui de Montréal en particulier, ressentent d'autant plus vivement les tribulations de l'évêque de Rome qu'ils sont eux-mêmes exposés aux critiques des rouges. Ceux-ci demeurent, dans les années 1850, une force politique redoutable. Héritiers des revendications démocratiques des patriotes, s'appuyant sur de solides assises électorales, dotés d'institutions essentielles au rayonnement de leurs idées, les rouges ne s'en laissent pas imposer facilement par le clergé. Celui-ci doit donc agir prudemment. Aussi n'est-ce pas tant les directives de $\mathrm{M}^{\mathrm{gr}}$ Bourget pour limiter l'influence du Pays qui doivent étonner que la timidité du geste. Objectivement, le prélat aurait été justifié de lancer une censure pénale contre ceux qui se portaient à la défense des agresseurs du pape; il aurait pu interdire officiellement le journal en invoquant les règles de l'Index. Cependant, la fragilité de la position sociale du clergé lui impose la prudence: il vaut mieux intervenir auprès des «bonnes âmes», dans leur for intérieur. La tactique à laquelle recourent donc d'emblée les évêques et à laquelle ils demeurent fidèles par la suite consiste à priver les mauvais journaux de leurs lecteurs. Les règlements disciplinaires du deuxième concile de Québec, tenu en 1854, stipulent, en effet, que lorsqu' «il circule de mauvais journaux 
dans une paroisse, les confesseurs doivent obliger leurs pénitents à les renvoyer; car un mauvais journal a bientôt gâté l'esprit d'un peuple». Mais les curés doivent user de prudence, car «c'est à l'Évêque qu'il appartient de juger de la nature de ces mauvais journaux, et de dénoncer au clergé, ou au peuple, ceux qu'on ne peut lire en conscience». En outre, «les curés ne doivent ni nommer ni désigner en chaire aucun de ces journaux qui pourraient se publier dans la province, sans y être autorisés par une direction écrite de l'Évêque. Il va sans dire que les propriétaires, éditeurs, imprimeurs et autres personnes qui contribuent directement et efficacement à répandre ces productions, jugées par l'Évêque immorales et irréligieuses, sont indignes de l'absolution ${ }^{31}{ }^{1}$. Ce décret sert de règle de conduite au clergé durant les décennies suivantes.

La raison pour laquelle les évêques préfèrent intervenir au for intérieur plutôt qu'au for externe est d'ordre social plus que spirituel. En effet, étant donné la pugnacité des rouges, à quoi servirait de fulminer des censures qui risqueraient de ne pas être efficaces. Le scandale n'en serait que plus grand. En 1868, l'évêque de SaintHyacinthe, $\mathrm{M}^{\mathrm{gr}} \mathrm{La}$ Roque, explique avec lucidité aux prêtres de son diocèse que l'épiscopat ne peut franchir certaines limites dans sa lutte contre les mauvais journaux de crainte que les éditeurs ainsi censurés publiquement intentent des poursuites judiciaires contre les évêques ${ }^{32}$. Pour de semblables raisons de statut social, le clergé refuse de s'afficher officiellement dans des journaux catholiques dont il encourage la fondation et qu'il accepte même de soutenir de ses deniers. En effet, pense-t-on, un «journal, rédigé par des laïques instruits et chrétiens, produirait plus de fruits, parce qu'il rencontrerait moins de préjugés que s'il était sous l'entière direction du clergé ${ }^{33}{ }^{\prime}$.

31. «Règlement disciplinaire adopté dans le second concile provincial de Québec», Mandements, lettres pastorales et circulaires des évêques de Montréal, 2 (1869): 467-468.

32. «Ah! si les Évêques pouvaient sans s'exposer à être iniquement molestés, user de leur droit, selon que l'entend l'éminent cardinal Barnabo dans la réponse qu'il a daigné me faire, il ne serait pas nécessaire de prendre une voie détournée pour atteindre notre but. Dans un pays que régiraient des lois véritablement catholiques, le chemin pour y arriver eût été plus direct et plus court: l'Évêque eût cité ces journaux à son tribunal; et le jugement aurait été décisif et sans appel, sauf l'appel dévolutif au Saint-Siège. En Canada, malgré la grande et belle liberté dont jouit l'Église, et dont il faut assurément bénir et louer Dieu, l'on est cependant exposé à voir quelquefois des hommes qui n'ont plus de catholique que le nom, oser menacer la parole ou l'action du supérieur ecclésiastique du tribunal civil, en s'appuyant sur une prétendue tolérance de la loi, qui ne devrait du moins exister qu'en faveur de ceux qui font profession d'appartenir à des croyances religieuses dont l'enseignement admet l'entière liberté des opinions!» («Circulaire sur les mauvais journaux et l'usure», Mandements, lettres pastorales et circulaires des évêques de Saint-Hyacinthe, 3 (1889): 15.

33. «Règlement disciplinaire adopté dans le second concile provincial de Québec», Mandements, lettres pastorales et circulaires des évêques de Montréal, 2 (1869): 468. 
Au cours des décennies suivantes, le rapport de force change. Les rouges deviennent de plus en plus marginaux dans un Parti libéral qui, dès les années 1870, se démarque officiellement du libéralisme européen. En revanche, le clergé québécois, dont les effectifs augmentent sensiblement et dont les établissements se multiplient dans les domaines de l'éducation et de la santé, renforce sa position sociale. À telle enseigne que $\mathrm{M}^{\mathrm{gr}}$ Fabre peut écrire, en 1882, que le clergé «est encore la classe dirigeante de notre société $e^{34} \gg$. La première condamnation officielle d'un périodique radical, Le Réveil, est prononcée dans le diocèse de Québec, où les rouges sont plus faibles. Monseigneur Taschereau récidive, en 1886, contre la réédition de La Lanterne, laquelle n'avait pourtant pas fait l'objet de condamnation officielle de la part de $\mathrm{M}^{\mathrm{gr}}$ Bourget dans sa version originale, en 1868-1869. En 1892 , les motifs qui amènent $\mathrm{M}^{\mathrm{gr}}$ Fabre à sévir contre Canada-Revue, bien que canoniquement fondés, ne sont guère plus impérieux que ceux qu'aurait pu invoquer $\mathrm{M}^{\mathrm{gr}}$ Bourget contre Le Pays. Or la disparition de Canada-Revue, peu de temps après sa condamnation, donne la mesure de l'influence dont dispose désormais le clergé é ${ }^{35}$. En outre, une décision judiciaire, rendue dans le procès intenté à l'archevêque de Montréal par le propriétaire de Canada-Revue, confirme la juridiction de l'évêque sur les fidèles catholiques et reconnaît qu'il n'abuse pas de son autorité en leur défendant, conformément au droit canon, de lire une publication qu'il juge répréhensible ${ }^{36}$. Par la suite, les évêques accordent plus de publicité à leurs condamnations: ils censurent les publications dans des mandements ou lettres pastorales adressés à l'ensemble des fidèles, plutôt que de les signaler dans des circulaires destinées au seul clergé. Toutefois, leur stratégie demeure la même: l'évêque prononce une censure dogmatique contre le périodique, dont il défend la lecture à ses fidèles, invoquant la plupart du temps les règles de l'Index ${ }^{37}$.

34. «Circulaire de Mgr l'évêque de Montréal au clergé de son diocèse», Mandements, lettres pastorales et circulaires des évêques de Montréal, 9 (1887): 397.

35. Au contraire, Le Pays se maintient une douzaine d'années après la condamnation privée de $\mathrm{M}^{\mathrm{gr}}$ Bourget et malgré la sourde lutte que lui livre le clergé. Il passe même à la périodicité quotidienne et affiche des tirages respectables pour l'époque.

36. «La Cie de publication du Canada Revue v. Mgr Fabre», Rapports judiciaires de Québec, 8 (1895): 195-282.

37. Ce sont les évêques de la province ecclésiastique de Québec, dans leur pastorale du 22 décembre 1896, qui se montrent les plus sévères. En effet, après avoir porté une censure dogmatique contre L'Électeur, ils menacent de censure pénale les fidèles qui continueraient de le lire et de suspense ipso facto tout clerc qui ferait de même («Lettre pastorale des archevêque et évêques de la province ecclésiastique de Québec au sujet du journal L'Électeur», La Semaine religieuse de Québec, 29,1 (2 janvier 1897): 3-5). En revanche, aucun texte ne contient une censure pénale explicite contre un éditeur. 
Outre le fait de dénoncer les franchises fiscales des communautés religieuses et de contester la mainmise du clergé sur l'éducation, Canada-Revue avait commis l'imprudence de dénoncer les mœurs légères d'un sulpicien, offrant ainsi à l'évêque, du point de vue canonique, un motif amplement suffisant de censure. Par la suite, cependant, la plupart des censures, notamment contre L'Électeur ou Le Pays, et la mise en garde adressée au Soleil et à La Vigie, ne se justifient guère que par la contestation du rôle de l'Église dans la société et de l'autorité du clergé, en particulier dans le domaine de l'éducation ${ }^{38}$. Or, l'évolution politique canadienne pousse l'épiscopat aux premières lignes dans la défense des droits scolaires des Canadiens français, tandis qu'au Québec, les changements sociaux font de l'éducation un enjeu de première importance, à propos duquel le clergé refuse de céder du terrain ${ }^{39}$. Les condamnations retentissantes de plusieurs publications opposées aux vues de l'épiscopat, en matière sociopolitique plus que religieuse, sont donc les indices d'un renforcement de la position sociale du clergé depuis le début des années 1860.

Évidemment, dans ce rapport de force, le clergé a marqué des points aux dépens d'autres groupes sociaux, et les radicaux du Parti libéral en ont surtout fait les frais. Progressivement marginalisés au sein même de leur parti, ils ont cessé de représenter une force politique. Dans le domaine particulier de l'édition, désormais dominé par la presse d'information à grand tirage, les journaux d'opinion n'intéressent plus qu'une fraction du lectorat. Leur discours est d'autant plus violent qu'il ne porte pas à conséquence, et l'épiscopat a beau jeu d'en interdire la lecture, étant donné que les organes officiels de leur propre parti hésitent à prendre leur défense.

À l'intérieur même de l'Église, les évêques renforcent leur autorité. Dès le début des années 1870 , soucieux d'empêcher «que notre presse canadienne, même celle qui se dit catholique, ne se lance imprudemment dans des discussions irritantes à propos de questions ou matières religieuses ou ecclésiastiques», les évêques rappellent aux

38. «Lettre pastorale des archevêque et évêques de la province ecclésiastique de Québec au sujet du journal L'Électeurn, La Semaine religieuse de Québec, 29,1 (2 janvier 1897): 3-5; «Mandement de Mgr l'Archevêque de Montréal au sujet du journal Le Pays», Mandements, lettres pastorales et circulaires des évêques de Montréal, 15 (1919): 182-184; «Lettre pastorale» [15 février 1911], Ma.ndements, lettres pastorales et circulaires des évêques de Québec, 10 (1906): 357-368.

39 Il faut voir un indice de cette importance croissante dans la publication, le 19 mars 1894, de la «Lettre pastorale de Nos Seigneurs les archevêques et évêques des provinces ecclésiastiques de Québec, de Montréal et d'Ottawa sur l'éducation», Mandements, lettres pastorales et circulaires des évêques de Montréal, 11 (1895): 646-693. 
journalistes qu'ils doivent s'abstenir de toute discussion sur ces sujets «sans avoir reçu instruction ou direction de qui de droit ${ }^{40}$ ». Lors de leur cinquième concile provincial, en 1873, ils adoptent un décret concernant la conduite des journalistes catholiques: ces derniers doivent traiter leurs adversaires avec charité, mais surtout se soumettre à l'autorité de l'ordinaire et ne jamais traduire un clerc devant le «tribunal incompétent de l'opinion publique ${ }^{41} »$. Ce décret, conforme aux règles canoniques en matière de censure préalable, est rendu nécessaire par l'influence de plus en plus grande de la presse. Dans les circonstances, les évêques ne peuvent plus se permettre de laisser les rédacteurs catholiques exprimer leur opinion comme bon leur semble sur des questions politico-religieuses. Ce décret reflète aussi la conception que les catholiques du XIX ${ }^{\mathrm{e}}$ siècle se font de l'Église, à savoir une société fortement hiérarchisée à l'intérieur de laquelle les laïcs ne sont que des subalternes dociles. Des rédacteurs de journaux catholiques, les évêques s'attendent donc à ce qu'ils se soumettent scrupuleusement à leurs directives. À défaut, ils peuvent priver le journaliste du soutien, moral et financier, de l'épiscopat. C'est l'expérience que vit François-Xavier-Anselme Trudel, en 1882, lorsqu'il veut lancer à Montréal un journal catholique ${ }^{42}$. Plusieurs évêques défendent à leurs clercs d'appuyer le projet, et même après la fondation de L'Étendard, $\mathrm{M}^{\mathrm{gr}}$ Fabre demeure réticent à l'endroit de la feuille de Trudel ${ }^{43}$.

40. «Avertissement au propriétaire du 'Courrier de Saint-Hyacinthe' au sujet des discussions religieuses dans les journaux" (Mandements, lettres pastorales et circulaires des évêques de Saint-Hyacinthe, 4 (1890): 547.

41. «Les devoirs de la presse, tels que tracés par notre dernier Concile de Québec peuvent se résumer ainsi: $1^{\circ}$ Traiter toujours ses adversaires avec charité, modération et respect, car le zèle pour la vérité ne saurait excuser aucun excès de langage; $2^{\circ}$ Juger ses adversaires avec impartialité et justice, comme on voudrait être jugé soi-même; $3^{\circ} \mathrm{Ne}$ point se hâter de condamner avant d'avoir bien examiné toutes choses; $4^{\circ}$ Prendre en bonne part ce qui est ambigu; $5^{\circ}$ Éviter les railleries, les sarcasmes, les suppositions injurieuses à la réputation, les accusations mal fondées, l'imputation d'intentions que Dieu seul connaît. Ce que l'Église n'a point condamné, on peut bien le combattre, mais non pas le mal noter. Quand il s'agit des autorités Ecclésiastiques ou Civiles, le langage doit toujours être convenable et respectueux. Il ne faut pas traduire devant le tribunal incompétent de l'opinion publique des établissements dont les Évêques sont les protecteurs et les juges naturels. Ajoutons que le Prêtre, et à plus forte raison, l'Évêque dans l'exercice de son ministère, n'est pas justiciable de l'opinion publique, mais de ses seuls supérieurs hiérarchiques. Si quelqu'un croit avoir droit de se plaindre, il peut toujours le faire devant ceux qui ont droit de lui rendre justice; du prêtre on peut appeler à l'Évêque, de celui-ci à l'Archevêque et de l'Archevêque au Souverain Pontife; mais il ne peut jamais être permis de répéter sur les journaux les mille et mille bruits que les excitations politiques font surgir comme les vagues d'une mer en furie» («Lettre pastorale des évêques de la province ecclésiastique de Québec», Mandements, lettres pastorales et circulaires des évêques de Montréal, 7 (1887): 213-214).

42. "Circulaire au clergé pour désavouer la fondation du journal L'Étoile du Matin», Mandements, lettres pastorales et circulaires des évêques de Saint-Hyacinthe, 7 (1895): 73-74.

43. "Circulaire de Monseigneur l'archevêque de Montréal au clergé de son diocèse», Mandements, lettres pastorales et circulaires des évêques de Montréal, 11 (1895): 431-435. 
$\mathrm{Au}$ début du $\mathrm{XX}^{\mathrm{e}}$ siècle, l'Église québécoise doit chercher de nouvelles façons d'être présente dans le monde. Pour propager une vision du monde fidèle à Rerum Novarum dans une société urbanisée, industrialisée et pluraliste, l'Église n'a d'autre choix que d'employer des moyens modernes et puissants, dont, au premier chef, la presse. La fondation de L'Action sociale, à Québec, et du Bien public, à TroisRivières, sont évidemment des réponses à l'invitation du pape. Mais elles sont aussi révélatrices des changements survenus au sein de l'Église québécoise. Dans les années 1850, sa situation financière est précaire, et les évêques doivent encore défendre l'institution de la dîme, dont le rendement est probablement faible ${ }^{44}$. Lorsqu'il est question de fonder des journaux catholiques, les évêques ne s'adressent qu'au clergé, et les feuilles catholiques ne font que vivoter. Au contraire, le quotidien catholique mis sur pied par $\mathbf{M}^{\text {gr }}$ Bégin en 1907 draine d'importantes ressources. L'évêché s'engage même dans le financement du journal qui emploie des dizaines de personnes, dont plusieurs prêtres ${ }^{45}$. Même si le clergé a resserré son emprise sur la presse catholique, les laïcs sont formellement invités à soutenir le journal en s'y abonnant et en versant leur écot au Denier de l'Euvre de la presse catholique. La publicité des commerçants catholiques, aussi, est activement sollicitée. En outre, l'évêque met son autorité morale au service de sa stratégie en menaçant de recourir à la censure pour protéger le nouveau quotidien contre des journaux comme $L e$ Soleil et La Vigie qui, victimes de la concurrence de L'Action sociale, ne se privent pas d'attaquer ce compétiteur encombrant.

\section{CONCLUSION}

Le clergé québécois est souvent présenté comme un groupe social particulièrement conservateur dans un monde où les valeurs libérales sont en progrès. L'image du censeur, souvent invoquée pour décrire les évêques, illustre bien cette conception. Toutefois, cette image ne se dégage du discours épiscopal que si l'on accentue fortement et, peutêtre, exagérément certains traits. Il ne fait pas de doute que les évêques tiennent à maintenir leur autorité sur le peuple qui leur a été

44. Par exemple, $\mathrm{M}^{\mathrm{gr}}$ Bourget consacre un long passage de sa pastorale du 31 mai 1858 contre les mauvais journaux à la défense de l'institution de la dîme (406-407).

45. Le chapitre sur l'histoire économique de l'Église québécoise reste à écrire, de sorte que les données nous manquent pour apprécier la situation financière des diocèses et des paroisses au début du $\mathrm{XX}^{\mathrm{e}}$ siècle. Cependant, il ne fait pas de doute que les ressources matérielles des institutions catholiques ont augmenté. Non seulement le clergé possède-t-il des assises matérielles plus solides, mais les revenus courants des églises locales sont sans doute à la hausse. À telle enseigne qu'il devient possible d'envisager, au début du siècle, la mise en place d'un véritable réseau de publications catholiques. 
confié et qu'ils prennent les moyens pour y parvenir. Comme la religion catholique invite le fidèle à conformer tous ses actes et toutes ses pensées à sa foi, il n'est pas étonnant que les évêques s'intéressent à l'ensemble de son existence et qu'ils cherchent à pénétrer jusque dans son for intérieur. La conception strictement hiérarchique que les évêques se font de l'Église réduit à presque rien l'autonomie spirituelle des fidèles. Cependant, considérées dans l'ensemble des communications officielles, les questions relatives à la culture ne sont pas souvent évoquées. Le thème de la presse, en particulier, n'est guère plus fréquent que celui des catastrophes naturelles. Entre 1764 et 1914, plus de 1800 feuilles périodiques ont été fondées au Québec. Un grand nombre de celles-ci éditent des dizaines, voire des centaines, de numéros chaque année. De ce nombre, une douzaine, tout au plus, ont fait l'objet d'une condamnation officielle. Il serait donc abusif d'imaginer, à partir de ce seul indice, des évêques obsédés par le contrôle des opinions.

Placé dans une perspective chronologique large, le discours des évêques québécois sur la presse révèle une stratégie cohérente. Contrairement à certains cllichés historiographiques, $\mathrm{M}^{\mathrm{gr}}$ Bourget, malgré ses opinions ultramontaines arrêtées, n'apparaît pas plus sévère que ses successeurs ou que $\mathrm{M}^{\mathrm{gr}}$ Taschereau, même si, à l'occasion, des raisons objectives de sévir s'imposaient. Incertain de son autorité, toutefois, il préfère user d'intimidation et évite de s'attaquer ouvertement à ses adversaires. Au tournant du siècle, appuyé sur des assises sociales et économiques plus solides, le clergé s'en prend vigoureusement à des adversaires qui sont particulièrement vulnérables ou qui, comme Le Soleil, menacent ses positions.

Quel que soit le contexte sociopolitique de leurs communications, les évêques demeurent respectueux des règles en vigueur à l'intérieur de l'Église romaine. La soumission à la hiérarchie est le précepte clé, mais, lorsque la déviance se manifeste, ils préfèrent agir sur le for intérieur plutôt que de recourir à des censures doctrinales et, a fortiori, pénales. Ils ne s'y résignent que si deux conditions sont réunies: le droit canon le justifie, et la soumission des fidèles est probable.

Bref, l'image du censeur, à l'occasion appliquée aux évêques québécois du XIX ${ }^{\mathrm{e}}$ siècle, ne se justifie guère par l'importance qu'ils auraient accordée, dans leur discours officiel, à la culture ou à la presse. Évidemment, cette attitude pourrait se manifester dans le traitement des autres questions, religieuses aussi bien que sociopolitiques. Pour tirer cette question au clair, il faudrait se livrer à l'analyse de l'ensemble de la correspondance officielle. De toute façon, l'analyse thématique du discours officiel des évêques ne nous révélera jamais qu'une infime partie de leurs interventions concernant 
la presse. Toutefois, l'intérêt de ce discours ne doit pas être sousestimé. Il est la résultante d'un processus d'évaluation et de sélection. Il exprime aussi, à l'occasion, le consensus des évêques ${ }^{46}$. Par ailleurs, plusieurs évêques ont échangé une abondante correspondance avec des éditeurs ou des journalistes. Dans ces lettres privées, s'exprime sans doute une pensée plus complète ou plus nuancée susceptible de confirmer nos hypothèses ou de nous permettre de les nuancer.

46. Sur le plan méthodologique, cependant, l'analyse de contenu ne justifie pas d'étendre les observations faites à propos des communications épiscopales au contexte social et religieux de leur production. L'interprétation proposée ici de la rationalité du discours épiscopal ne découle donc pas de l'analyse de contenu qui en est faite, mais repose plutôt sur des hypothèses suggérées par l'analyse et qui demandent vérification. 